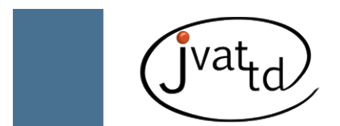

\title{
Proteomic characterization of the thermostable toxins from Naja naja venom
}

\author{
Binh DV (1), Thanh TT (1), Chi PV (1)
}

(1) Institute of Biotechnology, IBT, Vietnam Academy of Science and Technology, VAST, Hanoi, Vietnam.

\begin{abstract}
Naja naja snake venom presents abundant thermostable peptides. Many of them possess useful pharmacological activity that may be employed for drug development. For the proteomic characterization of such toxins, in the present study, Naja naja venom solution was heated up to $100^{\circ} \mathrm{C}$ for $10,30,60,120$, 180 and 300 minutes and protein fractions of non-heated and heated venom were analyzed by twodimensional nano-liquid chromatography coupled online with tandem mass spectrometry. After heating for 300 minutes, a total of 32 peptides were still detected in the supernatant. The identified peptides belong to the following groups: cardiotoxins, neurotoxins and cytotoxins. It was found that thermostable peptides are able to preserve their analgesic activity after a long heating time in formalin test. Mice injected with $15 \mu \mathrm{g} / \mathrm{g}$ of 60 -minute heated venom or with $25 \mu \mathrm{g} / \mathrm{g}$ of 300-minute heated venom revealed even a better analgesic activity than those treated with lidocaine.
\end{abstract}

Key words: Naja naja, snake venom proteome, thermostable peptides, mass spectrometry, analgesic activity.

\section{INTRODUCTION}

Naja naja is one of the most dangerous snake species in tropical and subtropical countries, where it provokes a high number of human deaths due to envenomations. Numerous biochemical studies on its venom have been carried out, so that different components were isolated from the venom toxins and structurally and biologically characterized (1-3). Results of previous research showed that Naja naja cobra venom contains several proteins and peptides with enzymatic and non-enzymatic activities that belong to different groups including phospholipases $\mathrm{A}_{2}$ (PLA2), cardiotoxins and neurotoxins. Currently, an increasing number of new proteins is being isolated from cobra venom and documented $(4,5)$. Moreover, due to recent developments in mass spectrometry (MS) for the identification of proteins, global analysis of snake venom has been performed, improving the knowledge on venom toxin composition. However, a main concern regarding the proteomic analysis of snake venom is that proteins and peptides present a wide range of quantitative distribution. Highly abundant proteins can mask and/or bind to those that are scarcer and thereby hinder their analysis. To the best of our knowledge, there is no method that can detect all proteins. Similarly, the quantitation of identified proteins depends on preparatory procedures of materials.

Protein components of snake venoms show different responses to changes of temperature. High-molecular-weight proteins are more affected, whereas low-molecular-weight proteins are more resistant to heat (6-8). The heating of a venom solution at $100^{\circ} \mathrm{C}$ for brief periods causes decrease of proteins and 
enzymes with molecular weight of at least $25 \mathrm{kDa}$ (8). Thermostable proteins found in venoms comprise peptides smaller than $10 \mathrm{kDa}$ that were detected in several snake species (9). According to Nawarak et al. (10), most proteins in elapid venoms have molecular masses below $20 \mathrm{kDa}$. Particularly, cobra venom is very rich in neurotoxins and cardiotoxins that comprise more than $50 \%$ of the venom protein (11). In the last 40 years, $\alpha$-neurotoxins from animal venoms have become an interesting research object, since numerous of these toxins possess useful pharmacological activities and could be employed for medical application. To date, data on global analysis of heat stable proteins from snake venoms have been limited. In the present work, the study on the heat stable subproteome from Naja naja cobra venom is reported. Furthermore, the results of our study on the characterization of this venom, including its toxicity and analgesic activity, are described.

\section{MATERIALS AND METHODS}

All chemicals and reagents were analytical grade. Bovine serum albumin, ammonium acetate and trypsin were purchased from SigmaAldrich (USA), formalin from Prolabor (France), acetonitrile (ACN) and formic acid (FA) from Merck (Germany). Crystal structures from $N$. naja venom were obtained from Dong Tam snake farm, Tien Giang city, Vietnam. White Swiss male mice (25-30 g) were employed as well.

\section{Heating Venom}

Seventy milligram of cobra venom was dissolved in $7 \mathrm{~mL}$ of two times distilled water. The solution was divided into seven microtubes and their caps were immediately closed. Six tubes, hanging in a stainless steel test tube rack, were set into boiling water. After a certain time of boiling $(10,30,60,120,180$ and 300 minutes) one tube was taken out of the water and immediately put in ice for 15 minutes. All the seven tubes were centrifuged at $15,000 \mathrm{~g} /$ minute for 30 minutes. After centrifugation, the pellet was discarded and the supernatant was applied to new tubes. The protein content of the supernatant was determined by the colorimetric method of Bradford (12), using bovine serum albumin as standard. The samples were kept at $-20^{\circ} \mathrm{C}$ until use.
Two-Dimensional Nano-Liquid Chromatography Coupled Online with Tandem Mass Spectrometry (2D nano-LC ESI-Q-TOF-MS/MS)

Ten micrograms of cobra venom (both nonheated and heated for 300 minutes) was digested by trypsin $(0.6 \mu \mathrm{g} / \mu \mathrm{L})$ and incubated overnight at $37^{\circ} \mathrm{C}$. The enzymatic digestion was stopped by acidification using $0.1 \%$ FA. The digested peptides were extracted by a solution that consisted of $60 \%$ ACN and $0.1 \%$ FA. Pools of these extractions were dried, redissolved in $30 \mu \mathrm{L}$ of $0.1 \%$ FA and this solution was loaded on the chromatographic column as described by Nägele et al. (13).

Samples were divided into 16 fractions by an online 2D nano-LC system (LC Packings Dionex, the Netherlands) developed for improved separation and hydrophobic peptide recovery. In the first step, the mixture of redissolved peptide in $0.1 \%$ FA was directly loaded on a strong cation-exchange (Bio-SCX) column $(\mathrm{C} 18,300 \AA, 5 \mu \mathrm{m}, 500 \mu \mathrm{m}$ ID x $15 \mu \mathrm{mm}, \mathrm{LC}$ Packings Dionex, the Netherlands) at a flow rate of $30 \mu \mathrm{L} /$ minute. Bound peptides were eluted with ammonium acetate gradient from 0 to $2 \mathrm{M}$. In the second step, peptides were then desalted and concentrated on a C18 Trap column (100 A, $5 \mu \mathrm{m}, 300 \mu \mathrm{m}$ ID x $5 \mu \mathrm{mm}$, LC Packings Dionex, the Netherlands), and further separated on a Vydac MS C18 reverse phase column (300 A, $5 \mu \mathrm{m}, 75 \mu \mathrm{m}$ ID x $150 \mathrm{~mm}$, Alltech, USA). The flow rate was maintained at $0.2 \mu \mathrm{L} /$ minute with solvent A containing $0.1 \%$ FA. After 12 minutes of washing, peptides were eluted in the reverse phase C18 column using a solvent B (85\% ACN, $0.1 \% \mathrm{FA}$ ) gradient: from 5 to $100 \%$ of solvent $\mathrm{B}$ in 65 minutes. After 2D nano-LC separation, peptides were independently analyzed by QSTAR $^{\circledR}$ XL MS/MS system (MDS SCIEX/ Applied Biosystems, Canada) equipped with a nano ESI source. The ion spectra of peptides obtained from mass spectrometry were analyzed with Mascot v1.8 software (Matrix Science Ltd., UK) and validated by MSQuant v1.5 software (http://msquant.alwaysdata.net).

\section{Acute Toxicity}

The acute toxicity of heated venoms (in $0.2 \mathrm{~mL}$ of saline solution) was tested by intraperitoneal injection in mice. The survival time of each experimental animal was recorded for 24 hours. LD50 was calculated by the comparison of doses injected with the observed survival time 
according to a mathematical scheme of Meier and Theakston (14).

\section{Inflammatory Pain Assay}

The analgesic effect of the snake venom was determined by formalin test as described by Zhang et al. (15), with a slight modification. Fifteen minutes prior to intraplantar injection of $15 \mu \mathrm{L}$ of $3.7 \%$ formalin into one hind paw, mice of three groups were intraperitoneally injected with 10 or $15 \mu \mathrm{g} / \mathrm{g}$ of cobra venom heated for 60 minutes (groups 1 and 2 ) or with $25 \mu \mathrm{g} / \mathrm{g}$ of venom heated for 300 minutes (group 3). Animals from two other groups were injected with lidocaine (20 $\mathrm{mg} / \mathrm{kg}$ ) or saline solution (vehicle control). Mice (two at a time) were observed for 50 minutes, and paw licking time was registered every five minutes. The acute phase (first) of the nociceptive response was quantified within the first five minutes. The inflammatory phase (second) was quantified from 20 to 30 minutes. For each dose of heated venom, at least 8 to 10 animals were tested.

\section{Statistics}

Statistical analysis of the difference between experimental and control groups was carried out using the Student's t-test.

\section{RESULTS}

\section{Comparison of Proteomes of Non-Heated and Heated Cobra Venom}

According to Rangel-Santos and Mota (7) and Sivaraman et al. (8), proteins with molecular weight heavier than $25 \mathrm{kDa}$ are not thermostable and tend to precipitate in short time after heating. In our experiments, the protein content of the supernatant in microtubes decreased drastically in the first 60 minutes of heating from $8.75 \mu \mathrm{g} / \mu \mathrm{L}$ (non-heated) to $5 \mu \mathrm{g} / \mu \mathrm{L}$ (heated venom) (Figure 1). After that time, the protein content changed slightly and reached the minimum after 180 minutes of heating.

In our experiments, from the peptide spectra of non-heated venom components, a total of 40 proteins matched with orthologous proteins in the NCBInr database. All the proteins were identified by at least two matching peptides. Proteins could be classified into eight different groups according to their putative biological activities - namely: cardiotoxin, cytotoxin, neurotoxin, cobra venom factor, L-amino acid oxidase, PLA2, natrin-1 and zinc metalloproteinase (Table 1). From the peptide spectra of heated venom components, only 32 peptides matched with orthologous proteins from the database. They were from three structurally similar groups: cardiotoxin, cytotoxin, and neurotoxin. Among them, the major group was cardiotoxin, represented by 17 different peptides. Obviously, five other groups - including cobra venom factor, L-amino acid oxidase, PLA2, natrin-1 and zinc metalloproteinase were less numerous - because of the heating.

\section{Acute Toxicity of the Heated Venom}

Heating treatment often causes changes in the protein structure. Therefore, snake venoms - that consist of more than $90 \%$ of proteins - are significantly altered. Thus, heating provoked structural changes in toxic components of heated venom, causing diminution of venom toxicity, so that its LD 50 value was increased. In a previous study by Achyuthan and Ramachandran (3), heating at $60^{\circ} \mathrm{C}$ for 100 minutes affected cardiotoxins of snake venom and the LD50 value was 1.92 times higher when compared to the nonheated toxin. Neurotoxins of Bacillus botulinus, which contain only one disulfide bridge, are more sensible to heat. Their heating at $50^{\circ} \mathrm{C}$ may diminish its toxicity by 4,000 times (16).

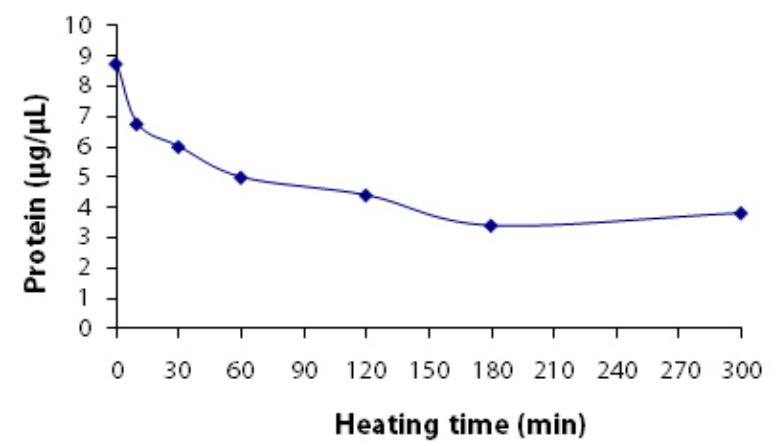

Figure 1. Protein content of the supernatant obtained from heated cobra venom. Naja naja venom was first heated at $100^{\circ} \mathrm{C}$ for $10,30,60,120$, 180 or 300 minutes, and then centrifuged at 15,000 $\mathrm{g} /$ minute for 30 minutes. The supernatant protein content $(\mu \mathrm{g} / \mu \mathrm{L})$ of each portion was determined by the colorimetric method of Bradford (12). 
Table 1. Proteins and peptides from non-heated and heated cobra venom identified by LC MS/MS

\begin{tabular}{|c|c|c|c|c|c|}
\hline \multicolumn{2}{|c|}{ Orthologous proteins } & \multirow{2}{*}{$\begin{array}{c}\text { Accession } \\
\text { number (Swiss- } \\
\text { Prot) }\end{array}$} & \multirow{2}{*}{$\begin{array}{l}\text { Molecular } \\
\text { mass (Da) }\end{array}$} & \multirow{2}{*}{ Score } & \multirow{2}{*}{$\begin{array}{l}\text { Peptide } \\
\text { matched }\end{array}$} \\
\hline Non-heated venom & Heated venom & & & & \\
\hline Cardiotoxin-1a & Cardiotoxin-1a & Q98957 & 9483 & 100 & 11 \\
\hline Cardiotoxin-2a & Cardiotoxin-2a & Q9PST4 & 9561 & 209 & 54 \\
\hline Cardiotoxin-2b & Cardiotoxin-2b & Q9PST3 & 9549 & 209 & 54 \\
\hline Cardiotoxin-3a & Cardiotoxin-3a & Q98959 & 9572 & 272 & 69 \\
\hline Cardiotoxin-3b & Cardiotoxin-3b & Q98960 & 9530 & 115 & 14 \\
\hline Cardiotoxin-3d & Cardiotoxin-3d & Q98962 & 9434 & 290 & 63 \\
\hline Cardiotoxin-4N & Cardiotoxin-4N & Q9W6W9 & 9606 & 99 & 44 \\
\hline Cardiotoxin-5 & Cardiotoxin-5 & Q98961 & 9593 & 214 & 63 \\
\hline Cardiotoxin-5a & Cardiotoxin-5a & 073857 & 9548 & 194 & 62 \\
\hline Cardiotoxin-5b & Cardiotoxin-5b & P60310 & 9562 & 194 & 62 \\
\hline Cardiotoxin-6 & Cardiotoxin-6 & 073858 & 7481 & 214 & 63 \\
\hline Cardiotoxin-7 & Cardiotoxin-7 & O73859 & 7513 & 213 & 57 \\
\hline Cardiotoxin-8 & Cardiotoxin-8 & Q91124 & 9407 & 124 & 46 \\
\hline Cardiotoxin-A1 & Cardiotoxin-A1 & P60304 & 9499 & 369 & 74 \\
\hline Cardiotoxin-A4 & Cardiotoxin-A4 & P01443 & 9591 & 194 & 62 \\
\hline Cardiotoxin-A4b & Cardiotoxin-A4b & P07525 & 7262 & 214 & 63 \\
\hline Cardiotoxin-A6 & Cardiotoxin-A6 & P80245 & 9487 & 135 & 37 \\
\hline Cobrotoxin-b & Cobrotoxin-b & P59275 & 7395 & 63 & 2 \\
\hline Cytotoxin SP13b & Cytotoxin SP13b & P60306 & 7244 & 216 & 29 \\
\hline Cytotoxin-1 & Cytotoxin-1 & P60305 & 7153 & 369 & 74 \\
\hline Cytotoxin-1 & Cytotoxin-1 & P01447 & 7243 & 172 & 69 \\
\hline Cytotoxin-2 & Cytotoxin-2 & P01445 & 7197 & 266 & 81 \\
\hline Cytotoxin-3 & Cytotoxin-3 & P24780 & 7197 & 123 & 60 \\
\hline Cytotoxin-4 & Cytotoxin-4 & P01452 & 7167 & 49 & 45 \\
\hline Cytotoxin-5 & Cytotoxin-5 & P24779 & 7106 & 233 & 68 \\
\hline Cytotoxin-6 & Cytotoxin-6 & P01465 & 7308 & 74 & 25 \\
\hline Cytotoxin-8 & Cytotoxin-8 & P49123 & 9430 & 135 & 37 \\
\hline Long neurotoxin 1 & Long neurotoxin 1 & P01391 & 8396 & 158 & 28 \\
\hline Long neurotoxin 3 & Long neurotoxin 3 & P25671 & 8398 & 158 & 28 \\
\hline Long neurotoxin 4 & Long neurotoxin 4 & P25672 & 8454 & 48 & 6 \\
\hline Long neurotoxin 5 & Long neurotoxin 5 & P25673 & 8428 & 48 & 6 \\
\hline $\begin{array}{l}\text { Weak tryptophan- } \\
\text { containing neurotoxin }\end{array}$ & $\begin{array}{l}\text { Weak tryptophan- } \\
\text { containing } \\
\text { neurotoxin }\end{array}$ & P82935 & 8189 & 51 & 30 \\
\hline Cobra venom factor & & Q91132 & 185940 & 381 & 10 \\
\hline L-amino acid oxidase & & Q4JHE3 & 59374 & 161 & 7 \\
\hline Natrin-1 & & Q7T1K6 & 27834 & 69 & 6 \\
\hline PLA2 isozyme 1 & & P00596 & 17116 & 236 & 5 \\
\hline PLA2 natratoxin & & A4FS04 & 13977 & 132 & 39 \\
\hline PLA2, acidic & & P15445 & 14135 & 147 & 41 \\
\hline PLA2, acidic D & & Q91900 & 16942 & 128 & 36 \\
\hline Zinc metalloproteinase & & Q10749 & 70412 & 80 & 2 \\
\hline
\end{tabular}


In another work by Rangel-Santos and Mota (7), heating at $100^{\circ} \mathrm{C}$ for 30 minutes raised the LD 50 of Crotalus durissus terrificus venom to a value 5.5 times higher when compared to that of non-heated venom.

In our experiment, the $\mathrm{LD}_{50}$ of the venom heated for ten minutes raised from 0.54 to 0.60 $\mu \mathrm{g} / \mathrm{g}$ (Figure 2), that is, 1.11 times higher when compared to non-heated venom. However, the value was still slightly smaller than the LD 50 of another cobra (Naja kaouthia) venom heated for the same time (6). After 30 and 60 minutes of heating, the LD 50 found were significantly different from 10.35 and $26.79 \mu \mathrm{g} / \mathrm{g}$, or 19.16 and 49.61 times higher when compared to non-heated venom. Heating for longer time $(120,180$ and 300 minutes) changed the LD50 of cobra venom to $31.86,33.49$ and 34.77 $\mu \mathrm{g} / \mathrm{g}$ respectively. These results showed that the venom diminished its toxicity drastically during the first 60 minutes of heating and the reduction was only vague after that. These findings suggest that after an hour of heating most toxic components in snake venom were already destroyed and heating could be used as a simple technique to detoxify cobra venom.

\section{Analgesic Activity of Heated Venom}

In cobra venom, the major components are cardiotoxins and neurotoxins. To date, more than 100 neurotoxins have been isolated and sequenced from Elapidae and Hydrophiidae snakes. In

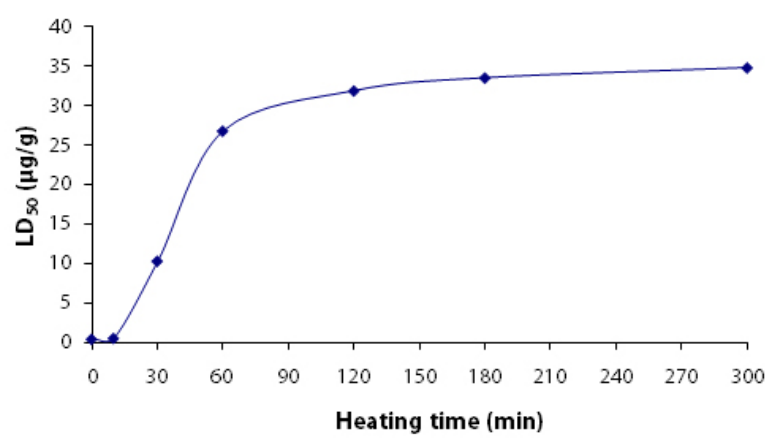

Figure 2. Change of $\mathrm{LD}_{50}$ value of heated cobra venom. Dissolved Naja naja venom was first heated at $100^{\circ} \mathrm{C}$ for $10,30,60,120,180$ or 300 minutes, than centrifuged at $15,000 \mathrm{~g} /$ minute for 30 minutes and the supernatant of each portion was injected into mice to determine the $L_{50}(\mu \mathrm{g} / \mathrm{g})$ according to the mathematical scheme of Meier and Theakston (14). prey, these toxins interfere with acetylcholine receptors and cause a blockade of neuromuscular transmission (17). Therefore, many of them were found to possess analgesic activity (18).

As the peptides might be thermostable, our experiments were set up to test if heated cobra venom could cause an analgesic effect on mice. So, mice were injected with 60-minute heated venom (dissolved in saline) in dose of 10 or 15 $\mu \mathrm{g} / \mathrm{g}$. Fifteen minutes after that, they were injected with formalin on hind paw and the times they licked their paws were counted in five-minute intervals. The results (Figure 3 ) showed that the licking time of mice injected with 10 or $15 \mu \mathrm{g} / \mathrm{g}$ of 60-minute heated venom are significantly shorter than that of mice injected with saline $(\mathrm{p}<0.05$ or $\mathrm{p}<0.001)$ and mice injected with lidocaine ( $\mathrm{p}$ $<0.05)$. This clearly showed that heated venom has an analgesic dose-dependent effect. Since the licking time of mice injected with a dose of $10 \mu \mathrm{g} / \mathrm{g}$ is significant longer than that of animals that received $15 \mu \mathrm{g} / \mathrm{g}(\mathrm{p}<0.05)$. It is interesting to observe that mice injected with $25 \mu \mathrm{g} / \mathrm{g}$ of 300-minute heated venom showed even a better analgesic response than those who received lidocaine $(\mathrm{p}<0.001)$.

Our findings suggest, for the first time, that cobra venom neurotoxins may preserve their analgesic activity after heating at $100^{\circ} \mathrm{C}$ not only for 60 minutes, but also for 300 minutes. However, it was also confirmed that heating provoked a reduction in the analgesic activity

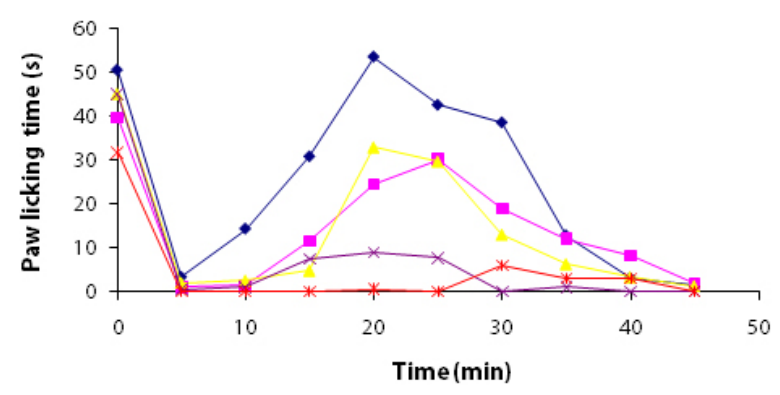

Figure 3. Analgesic activity of heated cobra venom on mouse inflammatory pain assay. Mice were first injected intraperitoneally with saline (dark blue squares); $20 \mu \mathrm{g} / \mathrm{g}$ dose of lidocaine (pink squares); $10 \mu \mathrm{g} / \mathrm{g}$ (yellow triangles) or $15 \mu \mathrm{g} / \mathrm{g}$ (violet " $\mathrm{x}$ ") of venom heated for 60 minutes; and $25 \mu \mathrm{g} / \mathrm{g}$ of venom heated for 300 minutes (red asterisk). After $15 \mathrm{~min}$ followed the formalin injection into a paw of mice and the paw-licking time was determined. 
because higher doses of venom are required in order to induce analgesic effects if the venom was heated for longer periods. It is not clear why and how the decrease happens. As documented by Stiles (19), the diminishment in analgesic activity by increasing temperature may be due to the reduction of binding activity of neurotoxin to acetylcholine receptors.

\section{DISCUSSION}

Snake venoms comprise a complex mixture of proteins and peptides, which respond different to temperature changes. High-molecular weight proteins are more affected by heating, whereas low-molecular weight ones are more resistant to temperature elevation (6-8). Heat-stable proteins have become an interesting research object because some of them possess useful pharmaceutical properties and could be used for medical application. For example, from the venom of Daboia russelli russelli, of the Viperidae family, the heat-stable 7.2-kDa cytotoxin ( $d r \mathrm{CT}-\mathrm{I})$ was isolated and proved to be antiproliferative (9). Numerous heat-stable neurotoxins and cardiotoxins - obtained from venoms of different cobra species - were already detected and structurally studied (3). Some of them presented anticancer potential, some antinociceptive properties and others even inhibited bone resorption $(4,18,20-22)$.

Snake venom heating was already carried out in several experiments. In such studies, the venom was heated in order to isolate a single component for structural and biological studies or to prepare toxic components for use as immunogens (6-8). In our experiment, we described for the first time the use of heating in a new approach to study thermostable subproteome of cobra snake venom. For that, cobra venom was first heated at $100^{\circ} \mathrm{C}$ for up to 300 minutes; the denatured proteins were removed by centrifugation. Both the heated and non-heated venom (supernantant containing mostly thermostable low-molecular weight peptides) were then digested with trypsin and analyzed by $2 \mathrm{D}$ nano-LC ESI-Q-TOF-MS/MS.

Subsequently, 40 proteins from non-heated Naja naja venom were identified. They belonged to eight different groups according to their biological activity. Our findings did not agree with previous ones, for example, Modahl et al.
(23) detected 30 proteins in Naja naja venom. Similarly, Li et al. (11), employing LC MS/MS, found 78 proteins in Naja naja atra venom, which were classified into five activity groups. Kulkeaw et al. (24) identified 61 proteins of 12 groups in Naja kaouthia venom by 2D LC MS/ MS. The different numbers of identified proteins in venoms may be due to species specificity in venom composition as described by Mukherjee and Maity (25).

In our experiment, proteins with molecular mass less than $10 \mathrm{kDa}$ (cardiotoxin, neurotoxin, and cytotoxin) comprised $80 \%$ of the total venom, while Li et al. (11) and Kulkeaw et al. (24) found, respectively, that 61 and $47.54 \%$ of the total venom consisted of low-molecular weight proteins. In the present study, the number of identified proteins that matched with orthologous proteins in the NCBInr database was reduced by heating. After 300 minutes of heating only 32 proteins were identified, fewer in comparison with nonheated venom. The most interesting point is that all these proteins are cardiotoxins, neurotoxins, and cytotoxins. Such findings provide clear evidence that these proteins are heat stable, but do not answer the question about their fraction of heated venom and if they could remain their biological activity.

It was documented in a previous study that a neurotoxin from cobra venom, the cobrotoxin, is relatively thermostable and might maintain $25 \%$ of its toxicity even after heating at $100^{\circ} \mathrm{C}$ for 30 minutes (1). In heated cobra venom, one can find only cardiotoxin, neurotoxin, and cytotoxin. Neurotoxin inhibits neurotransmission, leading to paralysis of skeletal muscles including those responsible for respiration, which causes the death of prey. However, many neurotoxins may be successfully used to relief pain (18). Cardiotoxin affects cardiac muscles and also possess antinociceptive activity (4). Therefore, we decided to test the acute toxicity and the analgesic activity of heated cobra venom.

The results showed that cobra venom drastically lost its toxicity after the first 60 minutes of heating, but maintained its lethal action even after heating for 300 minutes. We also observed that venom heated at $100^{\circ} \mathrm{C}$ for 60 and 300 minutes (in the doses of 15 and 25 $\mu \mathrm{g} / \mathrm{g}$ respectively) caused a significant better analgesic activity than lidocaine $(20 \mu \mathrm{g} / \mathrm{g})$ in mouse formalin test. Higher doses of venom 
must be used in cases of heating for 300 minutes to induce analgesic effect, since this heated venom demonstrated a reduction in its analgesic activity. This decrease may be due to the drop of binding activity of neurotoxin to acetylcholine receptors by increasing temperature as described by Stiles (19). Heating probably provoked changes in the structure of cobra venom components by decreasing their biological activity; however, how these changes occurred after different heating times, it should be investigated further.

\section{CONCLUSIONS}

The current findings provide clear evidence that Naja naja venom is abundant of thermostable peptides. After heating for 300 minutes, 32 different cardiotoxins, neurotoxins and cytotoxins were still identified by 2D nano-LC ESI-Q-TOFMS/MS. Although the venom drastically lost its toxic activities after the first 60 minutes of heating at $100^{\circ} \mathrm{C}$, some of its interesting biological and pharmaceutical activities still remained even after 300 minutes of continuous heating. In addition, in mouse formalin test, the venom heated for 60 and 300 minutes showed a better analgesic effect than lidocaine.

\section{ACKNOWLEDGEMENTS}

The work was supported by National Foundation for Science and Technology and carried out at the National Key Laboratory of Gene Technology (NKLGT), Institute of Biotechnology (IBT), Vietnam Academy of Science and Technology (VAST).

\section{COPYRIGHT}

(C) CEVAP 2010

\section{SUBMISSION STATUS}

Received: June 30, 2010.

Accepted: August 11, 2010.

Abstract published online: August 13, 2010.

Full paper published online: November 30, 2010.

\section{CONFLICTS OF INTEREST}

There is no conflict.

\section{FINANCIAL SOURCE}

National Foundation for Science and Technology provided the financial grants.

\section{ETHICS COMMITTEE APPROVAL}

The present study was approved by the Ethics Committee of the Institute of Biotechnology (IBT), Vietnam Academy of Science and Technology (VAST).

\section{CORRESPONDENCE TO}

PHAN VAN CHI, Protein Biochemistry Laboratory and Proteomics Unit, Institute of Biotechnology (IBT), Vietnam Academy of Science and Technology (VAST), 18 Hoang Quoc Viet Rd, Hanoi, Vietnam. Phone/fax: +84 4 37913657.Email: chi@ibt.ac.vn.

\section{REFERENCES}

1. Yang CC. Crystallization and properties of cobrotoxin from Formosan cobra venom. J Biol Chem. 1965;240(4):1616-8.

2. Walkinshaw MD, Saenger W, Maelicke A. Threedimensional structure of the «long» neurotoxin from cobra venom. Proc Natl Acad Sci USA. 1980;77(5):2400-4.

3. Achyuthan KE, Ramachandran LK. Non-identity of reaction centres for pyrophosphatase and toxic actions of cardiotoxin II: The status of cardiotoxin II as a metalloprotein. Indian J Biosci. 1983;5(1):1-6.

4. Jiang WJ, Liang YX, Han LP, Qiu PX, Yuan J, Zhao SJ. Purification and characterization of a novel antinociceptive toxin from cobra venom (Naja naja atra). Toxicon. 2008;52(5):638-46.

5. Ponnappa KC, Saviour P, Ramachandra NB, Kini RM, Gowda TV. INN-toxin, a highly lethal peptide from the venom of Indian cobra (Naja naja) venom: isolation, characterization and pharmacological actions. Peptides. 2008;29(11):1893-900.

6. Seatang T, Suttijitpaisal P, Ratanabanangkoon K. Preparations of toxic components from Naja kaouthia venom by selective heat denaturation. J Nat Toxins. 1998;7(1):37-44.

7. Rangel-Santos AC, Mota I. Effect of heating on the toxic, immunogenic and immunosuppressive activities of Crotalus durissus terrificus venom. Toxicon. 2000;38(10):1451-7.

8. Sivaraman T, Kumar TK, Hung KW, Yu C. Comparison of the structural stability of two homologous toxins isolated from the Taiwan cobra (Naja naja atra) venom. Biochemistry. 2000;39(30):8705-10.

9. Gomes A, Choudhury SR, Saha A, Mishra R, Giri B, Biswas AK, Debnath A, et al. A heat stable protein toxin (drCT-I) from the Indian viper (Daboia russelli russelli) venom having 
antiproliferative, cytotoxic and apoptotic activities. Toxicon. 2007;49(1):46-56.

10. Nawarak J, Sinchaikul S, Wu CY, Liau MY, Phutrakul S, Chen ST. Proteomics of snake venoms from Elapidae and Viperidae families by multidimensional chromatographic methods. Electrophoresis. 2003;24(16):2838-54.

11. Li S, Wang J, Zhang X, Yan R, Wang N, Zhao K et al. Proteomic characterization of two snake venoms: Naja naja atra and Agkistrodon halys. Biochem J. 2004;384(Pt 1):119-27.

12. Bradford MM. A rapid and sensitive method for the quantitation of microgram quantities of protein utilizing the principle of protein-dye binding. Anal Biochem. 1976;72:248-53.

13. Nägele E, Vollmer M, Hörth P. Two-dimensional nano-liquid chromatography-mass spectrometry system for applications in proteomics. J Chromatogr A. 2003;1009(1-2):197-205.

14. Meier J, Theakston RD. Approximate LD 50 determinations of snake venoms using eight to ten experimental animals. Toxicon. 1986;24(4):395401.

15. Zhang MM, Green BR, Catlin P, Fiedler B, Azam L, Chadwick A et al. Structure/function characterization of micro-conotoxin KIIIA, an analgesic, nearly irreversible blocker of mammalian neuronal sodium channels. J Biol Chem. 2007;282(42):30699-706.

16. Zhou B, Pellett S, Tepp WH, Zhou H, Johnson EA , Janda KD. Delineating the susceptibility of botulinum neurotoxins to denaturation through thermal effects. FEBS Lett. 2008;582(10):1526-31.

17. Lewis RL, Gutmann L. Snake venoms and the neuromuscular junction. Semin Neurol. 2004;24(2):175-9.
18. Liang YX, Jiang WJ, Han LP, Zhao SJ. Peripheral and spinal antihyperalgesic activity of najanalgesin isolated from Naja naja atra in a rat experimental model of neuropathic pain. Neurosci Lett. 2009;460(3):191-5.

19. Stiles BG. Acetylcholine receptor binding characteristics of snake and cone snail venom postsynaptic neurotoxins: further studies with a non-radioactive assay. Toxicon. 1993;31(7):82534.

20. Tsai CH, Yang SH, Chien CM, Lu MC, Lo CM, Lin $\mathrm{YH}$ et al. Mechanisms of cardiotoxin lllinduced apoptosis in human colorectal cancer colo205 cells. Clin Exp Pharmacol Physiol. 2006;33(3):177-82.

21. Chien CM, Lin KL, Su JC, Chang LS, Lin SR. Inactivation of epidermal growth factor receptor and downstream pathways in oral squamous cell carcinoma Ca9-22 cells by cardiotoxin III from Naja naja atra. J Nat Prod. 2009;72(10):1735-40.

22. Wu PL, Lee SC, Chuang CC, Mori S, Akakura N, Wu WG, et al. Non-cytotoxic cobra cardiotoxin A5 binds to alpha(v)beta3 integrin and inhibits bone resorption. Identification of cardiotoxins as non-RGD integrin-binding proteins of the Ly-6 family. J Biol Chem. 2006;281(12):7937-45.

23. Modahl CM, Doley R, Kini RM. Venom analysis of long-term captive Pakistan cobra (Naja naja) populations. Toxicon. 2010;55(2-3):612-8.

24. Kulkeaw K, Chaicumpa W, Sakolvaree Y, Tongtawe $\mathrm{P}$, Tapchaisri P. Proteome and immunome of the venom of the Thai cobra, Naja kaouthia. Toxicon. 2007;49(7):1026-41.

25. Mukherjee AK, Maity CR. Biochemical composition, lethality and pathophysiology of venom from two cobras: Naja naja and $N$. kaouthia. Comp Biochem Physiol B Biochem Mol Biol. 2002;131(2):125-32. 